\title{
INTERPERSONAL SKILLS DEVELOPMENT IN GENERATION Y STUDENT NURSES: A LITERATURE REVIEW
}

\author{
Varshika M Bhana \\ Postal address: \\ Department of Nursing Science \\ University of Pretoria \\ HW Snyman Building, Room 8-28 \\ Gezina \\ Pretoria \\ 0001 \\ South Africa \\ Office Telephone: +27 123542125 \\ Fax number: +27 123541490 \\ E-mail: varshika.bhana@up.ac.za
}

\section{$\underline{\text { ABSTRACT }}$}

Background: Student nurses require training in the development of the interpersonal skills that are required for therapeutic nurse-patient relationships. This training should be provided within the basic education of nurses in a higher education institution. As the birth years of Generation $Y$ range from the early 1980 s to the late 1990s this generation is of the age group that enrols in higher education institutions. The unique learning needs of this generation necessitate a review of teaching strategies used in the development of interpersonal skills.

Objectives: The aim of this study is to present a literature review on the significance and development of interpersonal skills in Generation $Y$ nursing students through nursing education.

Methodology: Literature searches were conducted on databases - with the use of Cumulative Index of Nursing and Allied Health (CINAHL), Clinical key, PubMed and Google Scholar - using specific keywords and a timeframe of 2005 to 2013. All relevant articles were read critically.

Findings: Interpersonal skills are at the core of the nurse-patient relationship. Meaningful interaction is recognised in Swanson's theory of "informed caring". 
Debates, case studies, role-playing, storytelling, journaling, simulations and web page links to audio and video clips are some of the teaching strategies which can develop the interpersonal skills needed for meaningful interactions.

Conclusion: Teaching strategies embedded in the deconstruction pedagogies stimulate critical, analytical thinking through methods which complement the unique learning styles of Generation Y learners.

\section{KEYWORDS}

Interpersonal skills, Communication, Nurse patient relationship, Nurse education, Generation Y, Millennium generation, Practice development

\section{INTRODUCTION}

A relationship that develops between a nurse who is competent in interpersonal skills and the patient will result in empowerment of the patient, as the patient perceives an increased sense of solidarity, security, health and wellbeing through a therapeutic relationship (Halldorsdottir, 2008).

Communication is the foundation of all human relationships (Searle et al, 2009). It is through communication between the nurse and the patient that a bond is created (Halldorsdottir, 2008). These views are shared by Legg (2011), who states that a relationship of trust can be established through good communication. Through trust the patient can feel confident in the ability of the nurse and have faith in the nurse's goodwill. Good communication forms the foundation for a therapeutic and supportive relationship between the nurse and the patient (Searle et al, 2009).

Interpersonal skills are described as skills that are required for communication and interaction with others and these skills play a significant role in creating a therapeutic nurse-patient relationship (Stein-Parbury, 2000). In South Africa, The scope of practice for nurses and midwives requires professional nurses to 'initiate and maintain a therapeutic relationship' (Department of health, 2013, p.5). Therefore the 
interpersonal skills required for a therapeutic nurse patient-relationship are facilitated during the course of the undergraduate nursing programme.

Individuals of Generation $Y$ are of the age where they continue to enter into universities and colleges. Learners who belong to the $\mathrm{Y}$ generation are known for communicating and interacting through social networking sites. Generation $Y$ learners are technologically competent, collaborative and work well in teams. They like to express their opinions and want creative ways to solve problems (Gibson, 2009). Teaching strategies should harmonise with the values and learning needs of Generation Y learners.

The training and competency evaluation of interpersonal skills is an integral part of undergraduate nurse training. It is therefore important to identify the unique learning needs of Generation $Y$ learners and the appropriate teaching strategies for interpersonal skill development to take place successfully (White \& Kiegaldie, 2011).

\section{PROBLEM STATEMENT}

Communication between the youth has been found to increasingly occur through social networking sites. Sites such as Facebook, Twitter and MySpace are increasingly utilised by Generation Y (Roblyer et al, 2010). Social networking sites have created a platform for interaction and networking with friends and family and, when used responsibly, have been found to increase closeness to friends and cultivate a sense of belonging (DeAndrea et al, 2012).

Instant messaging, sending photographs from cell phones and playing online games are just some of the ways in which Generation $\mathrm{Y}$ interact with one another. Many may even prefer online communication to a telephonic conversation. For this generation online communication does not exclude face-to-face communication and neither do they consider on-line communication to be impersonal (Oblinger \& Hawkin, 2005)

However, does the level of social interaction on social networking sites influence the interpersonal skills that these young individuals require in a working environment? In the nursing profession student and professional nurses are required to interact with 
patients and health care professionals in order to provide nursing care. This interaction involves face-to-face communication (Stein-Parbury, 2000). During the education of nursing students apart from development of knowledge and psychomotor skills, interpersonal skills needed for communication in a therapeutic nurse-patient relationship also need to be developed (Ward et al, 2012).

Taking into consideration the unique characteristics and needs of the Generation $Y$ learner this review article will consider the question of how interpersonal skills in Generation $Y$ learners can be developed in order to prepare them for interaction with patients where they will be required to act with creativity, compassion, tolerance and honesty.

The following research questions were used to guide the literature search:

1. What are the current teaching strategies for interpersonal skills development in nursing programmes?

2. What are teaching strategies which will develop interpersonal skills of Generation $Y$ nursing students?

\section{METHODOLOGY}

Literature searches were conducted on databases Cumulative Index of Nursing and Allied Health (CINAHL), Clinical key, PubMed and Google Scholar. The following keywords were used during searches: "nursing care", "caring", "nurse-patient relationship", "interpersonal skills", "communication”, "Language”, "Generation Y", "millennial generation", "social networking", "nurse education", "student nurse", "current teaching methods", "teaching methods", "interpersonal skills training" and "practice development". The timeframe covered was from 2005 to 2013. Sixty three relevant articles were read critically.

Searches were initially broad and were narrowed with the use of more specific search topics. The researcher retrieved relevant articles that were read, abstracted, and critiqued by analysing and synthesising the information. The articles were sorted into different categories. Similar to analysing qualitative data, important themes were identified. The thematic analysis allowed the researcher to find patterns and 
regularities, as well as inconsistencies. The patterns that were of the greatest relevance to the phenomenon under investigation were then pursued to develop an argument and provide a context for the research.

\section{FINDINGS FROM THE LITERATURE REVIEW}

Generation $Y$ birth years range from the early 1980s to the late 1990s (White \& Kiegaldie, 2011). This generation has also been referred to as the "millennium generation" or the "millennials" (Lower, 2008) and are known for growing up in a high-technology environment (Liu et al, 2011). Their social interaction and communication has been greatly influenced through social networking sites (O'Keeffe et al, 2011).

The interpersonal skills necessary for the development of a therapeutic nurse-patient relationship are facilitated during the training of student nurses. The literature review that follows will address the significance of interpersonal skills and the development of interpersonal skills in Generation $\mathrm{Y}$ nursing students through nursing education.

\section{The significance of Interpersonal skills}

The nurse uses scientific knowledge and skills in her provision of care to the patient. Central to nursing practice is the role of caring (Potter \& Perry, 2007). This is so because patients with physical and emotional distress are in need of care, which nurses are mandated to provide (Askinazi, 2004). The caring approach of the nurse during interaction with the patient forms the basis of the nurse-patient relationship (Potter \& Perry, 2007). Hagerty and Patuskt (2003) concur that the nurse-patient relationship is considered to be the foundation of nursing care.

At the core of the nurse-patient relationship is interpersonal skills, which facilitate the development of a constructive and effective relationship. The ability to interact effectively with another person is referred to as "interpersonal skills" (Johnson, 2009). Self-disclosure, trust, communication, expression of feelings and helpful listening and responding, as some of the interpersonal skills that can be developed further in order to establish and maintain therapeutic relationships. 
Swanson's theory of nursing as "informed caring" recognises the psychosocial actions that take place during the rendering of nursing care. Meaningful interaction is described by Stein-Parbury (2000) through the five processes of caring in the theory of "informed caring". The first process focuses on the nurse's intrinsic belief in people and the meaning that the nurse attaches to health events which develops through an inherent process of self-awareness. Once the nurse has an established viewpoint she is able to understand the meaning of the health of patients.

In the second process the nurse uses interpersonal skills such as listening, understanding and exploring in order to 'know' patients. The third process is referred to as "being with" patients and this is achieved through being fully present and available to patients. Interpersonal skills such as attending and listening can be effective in this process.

Once the nurse is present 'with' patients the last two processes of the theory, which involve "doing for" patients and "enabling" patients to do for themselves can be applied. While "doing for" patients is associated with caring for the physical needs, it is also related to the nurses' psychosocial interaction with the patient during interventions. Interaction at this stage is dependent on the development of interpersonal skills such as comforting and supporting. While the interpersonal skills used to encourage patients to participate in their own health care is required in the final process of "enabling" patients in the theory of "informed caring"

In a study conducted on patient participation in nursing care Larsson et al (2007) found that patient participation in his or her own care depended on interpersonal interaction between the nurse and the patient. The nurse-patient relationship must be of such a nature that it enables patients to participate in their own care. In order for patients to participate in their care they must have insight into their condition and care. This category was termed "insight through consideration" and the knowledge of the patient was considered to be augmented by the nurse's communication of relevant information to the patient in a safe environment.

Finfgeld-Connett (2007) also identifies a similar process in nursing care where the nurse displays expert nursing practice by assessing the needs of the patient and then implementing appropriate interventions. These interventions may involve doing, advocating and empowering patients to care for themselves. Expert nursing, 
interpersonal sensitivity and intimate relationships are identified as the attributes of the process of nursing. The nurse allows for interpersonal sensitivity by practicing attentive listening, eye contact, touch and verbal reassurance. "Intimate relationship" refers to the nurse-patient relationship in which caring has developed.

The nurse communicates caring and concern for the patient through the confidence and efficiency with which she performs nursing care. Simple actions such as ensuring a environment conducive to healing exits and addressing the patient in a respectable manner creates trust in the nurse-patient relationship (Searle et al, 2009).

Thus far this literature review affirms that there is a process to caring and that caring does not occur haphazardly. In order to practice caring, nurses require interpersonal skills, which can be developed through appropriate training. A multi-dimensional nursing education programme in which the nursing student acquires knowledge, psychomotor skills and gains the appropriate attitudes and necessary interpersonal skills for caring practices is essential.

Taking into consideration the unique learning needs of Generation $Y$ learners during the facilitation of interpersonal skills is essential for ensuring successful learning takes place.

\section{Development of interpersonal skills}

Each generation has unique characteristics, values, strengths and weaknesses. Generation $Y$ has been described as multitaskers and collaborators. They work well in teams and are attracted to activities that encourage social interaction. For Generation $\mathrm{Y}$ technology is not merely a tool for tasks but it is entrenched in their lives and lifestyle. As a result they are always connected and communicating (Skiba, 2005).

Generation $\mathrm{Y}$ learners are future orientated. They have been described as determined, optimistic and have a hopeful point of view. When involved in problem solving, generation $Y$ learners prefer positive and creative options (Gibson, 2009). They are known to work in teams. During team work they abide by the rules and 
have respect for authority. At the same time they are self-reliant and questioning and can challenge authority (Walker et al, 2006).

The $\mathrm{Y}$ generation comprises of progressive thinkers who are able to process information quickly. However, they have a short attention span and get bored easily (Lower, 2008). Their tendency to multitask may disadvantage them as it prevents them from focusing on one activity and difficulties in traditional communication and reading and writing may be experienced (Pardue \& Mogan, 2008).

A study conducted by Walker et al (2006) on the generational preferences for teaching strategies found that both Generation $X$ and $Y$ learners preferred lectures to group work or web based learning and coursework. The study found that learners indicated significant levels of trust in lecturers to tell them what to do. Learners also indicated that they learnt for a grade and not for the sake of learning. This is contrary to literature which describes generation $\mathrm{Y}$ learners as technologically competent, self-reliant and team players.

Lower (2008) acknowledges the challenges that Generation $Y$ nurses may pose but also recognises that this generation has the confidence and technological understanding and practicality necessary for the progression of nursing. In light of the above, nurse educators should consider the strengths of Generation $\mathrm{Y}$ learners in order to improve teaching strategies and improve the retention and advancement of learners.

Becker et al (2006) states that traditional teaching strategies of interpersonal skills involve lecturing in a classroom and the practice of the skills during the provision of patient care in clinical practice. Evaluation of the competency may involve a written evaluation which focuses on knowledge of facts on the skill. Current practices also include mentoring of student nurses in clinical practice.

Advancements in teaching strategies have led to distance education, self-directed computerised education and clinical simulation (Arhin \& Johnson-Mallard, 2003). While these teaching strategies are in keeping with advancements in technology they may remove the learner from the element of human connectedness if not managed well. Therefore, mentoring of interpersonal skills in clinical practice together with the use of more advanced teaching strategies is encouraged. 
In a study conducted by Boschma et al (2010) lecturers stated that they taught communication theory through lectures and hands-on practice took the form of written assignments, journaling, role-play and video tape analysis. Learners also emphasised hands-on practice and identified audio- or video-tape analysis and roleplay as the desired strategies.

Learners found that lecturers emphasised the importance of good communication skills but observed that only a brief amount of time was spent on facilitating communication skills. Lecture halls were not a conducive teaching learning environment and a teaching learning environment more conducive to interaction and hands-on practice was suggested by learners.

Nursing practice involves the provision of care which is evidence based. Nursing education aims to develop learners into professional nurses who have the knowledge, skills and critical reasoning skills necessary for patient care which is evidence based. Therefore, nurse educators have the responsibility to develop the learning environment and enhance teaching strategies so as to develop the learner into a professional nurse who can provide evidence based care to patients. Nurse educators have to create a learning environment in which students are actively involved. Taking into consideration the learning styles of Generation Y learners, teaching strategies which support a culture of reading, critical, analytical thinking and reasoning and evidence based practice in all areas of nursing including interpersonal skills development need to be adopted.

Arhin and Cormier (2007) recommend the application of deconstruction pedagogies in nursing education to stimulate critical thinking. Debates, case studies, roleplaying, simulations, journaling and web page links are some approaches which motivate the learner to learn and give the learner the opportunity to analyse and deconstruct information. Generation $Y$ learners who are described as visual learners can use concept mapping to enhance critical analysis and understanding of the concepts within interpersonal interactions. Journaling of interpersonal interactions in clinical practice can be further enhanced by creating blogs where learners can share their experiences. In this way the unique learning styles and the most appropriate teaching strategies complement each other and stimulate learning. 
Boschma et al (2010) recommends that curriculum concept mapping be done to clearly reflect the embedded communication education content. Hands-on practice is highly recommended with dedicated labs and simulation resources. Continuous evaluation of communication skills, including critical self-reflection, is suggested. Both lecturers and learners highly recommended communication competencies in the undergraduate programme to enable the delivery of safe, quality practice. Jones (2008) concurs that effective communication skills are fundamental to safe and effective outcomes in patient care. A quasi-experimental, pre-test, post-test study conducted by Jones (2008) found that the group of nursing students who were taught through problem-based learning (PBL) demonstrated a highly significant increase in critical thinking and communication skills. Learners reflected that they learnt more in groups then individually and that PBL enhanced their communication skills. The learning opportunities offered during PBL allowed learners to reflect on and get immediate feedback on their communication skills. Learners also reported that this teaching strategy allowed them to gain confidence in their communication skills.

One of the challenges experienced by Generation $Y$ is the sorting of the volumes of information that is available to them through social media Pardue and Morgan (2008). PBL can equip learners with the necessary skills to search for and critique information. Given the characteristics and connectedness of Generation Y, PBL would suit the learners' needs for interactive teaching (White, 2011) and their need for immediate responses (Skiba, 2005).

Pardue and Morgan (2008) identify active engagement as a learning need in Generation $\mathrm{Y}$ learners and thus encourage the integration into teaching of experiential learning through the use of active questioning, group work, multi-media and hands-on activities.

Interpersonal skills are practical skills therefore teaching strategies should involve activities which allow opportunities for active participation. Through active participation the learner gains new knowledge by doing. The teaching strategy used in the Program to Enhance Relational and Communication Skills involves active participation of learners (Gunderman \& Brown, 2012). 
Learners participate actively in this program by analysing video clips of health care professional and patient interactions. The video clips have examples of both good and poor interpersonal and communication skills. The program also uses role-play exercises called "enactments" in which the learner interacts with professional actors who portray a patient or family members.

A debriefing session between learners and actors which follows the "enactments" allows opportunity for feedback, sharing of experiences and perceptions which also contributed to learning and professional growth (Gunderman \& Brown, 2012).

McKenny (2011) states that on-line videos can be used to display visual examples of interpersonal and communication skills which are needed to develop a trusting, caring relationship with patients. Learners had access to the on-line video for the duration of the course and could view the video for an unlimited number of times. McKenny (2011) found that learners who watched the on-line video several times performed above average on the psychomotor examination.

Interpersonal interaction does not occur in isolation to nursing care interventions but rather, the nurse has to interact with the patient during the provision of nursing care. Student nurses are taught several psychomotor skills such as urinary catheterisation, intravenous cannulation, suturing of a laceration and wound care. These and several other skills are taught and practiced in a skills lab on bench-top models. As interpersonal interaction with a bench-top model is not realistic often these skills are taught in isolation to the psychomotor skills.

The integrated procedural performance instrument has been used to teach and evaluate psychomotor skills and interpersonal skills by using both the bench-top model and a simulation patient in an integrated manner. Through a randomised controlled trial Moulton et al (2009) found that the use of the integrated procedural performance instrument significantly improved communication and interpersonal skills in the experimental group compared to the control group. The control group was only taught and evaluated on the psychomotor skill and when compared to the experimental group no difference was found in the performance of the psychomotor skill. The implication is that even though the participants of the experimental group had to perform two tasks, their performance on the psychomotor skill was not negatively influenced. 
Simulation patients allow learners to practice skills in a safe and controlled environment and to develop comfort and confidence in the clinical skill. Remediation of the skill is also possible as the learner is given immediate feedback (Becker et al, 2006).

Technological advancements have led to the development of advanced learning technologies such as Second Life ${ }^{\circledR}$ which uses the virtual environment as a space where simulations can be done. Based on a scenario a virtual environment can be created. The technology allows a three dimensional virtual environment in which learners can interact with each other over a topic of interest. Second Lifeß has been identified as an environment in which simulations and role-plays concerning interpersonal skills can be done.

In a study conducted by Aebersold et al (2012) learners found the learning experience through Second Life ${ }^{\circledR}$ to be beneficial although they did experience technical difficulties such as a slow chat texting due to poor typing skills of some students. Aebersold et al (2012) recommend that the benefits of Second Life® as a learning tool be further explored as it can be useful in the simulation of a multidisciplinary care environment. The virtual environment allows for critical skills such as interpersonal skills to be practiced in a safe environment preparing the learner for a real life situation. Further Second Life® allows for interactive training and learning to take place but does not require learners to be physically in the same place such as in a simulation lab.

Lee-Hsieh et al (2007), developed a caring curriculum in Taiwan which used novels, films, role modelling, dialogue, discussions and journaling as teaching strategies to apply concepts of caring. Massage and acupressure are examples of the caring skills taught. Lecturers role modelled caring by demonstrating caring in their interactions with learners. These teaching strategies encourage experiential learning, engage the learner and give the learner control over their learning as the strategies engage the learner and make learning meaningful for a Generation $Y$ learner (Arhin \& Johnson-Mallard, 2003).

The teaching strategies discussed above involve the use of scenarios. The scenarios can be developed to meet the specific outcomes of interpersonal skill development such as the development of trust, expression feelings, compassion, 
empathy, respect and various methods of communication. Language is an important communication skill which can be a barrier when the patient and the nurse do not share a common language. The above teaching strategies can be used to address such challenges and through student-student and student-lecturer interaction teach alternate methods of communication.

Lecturers also need to consider the learners proficiency in the medium of instruction. English may not be the first language of the learner yet the nature of the health care setting requires learners and professionals to have reading, writing, listening and speaking skills in English. Guhde (2003) implemented tutor sessions which focused on communication in English which was incorporated with medical terminology. The learner listened to audio tapes on reading, writing, listening and speaking English. The case study found improvement in language proficiency.

The teaching strategies discussed thus far allow for a controlled environment in which learners are prepared with knowledge and psychomotor skills for interpersonal interactions. These skills need to be successfully implemented in clinical practice. Therefore, learning will continue in clinical practice. Active Learning takes place in the clinical practice and involves principles of personal reflection, dialogue with others, intentional action and enabling of learning experiences with others in the workplace. Through personal reflection the learner recognises their own thoughts and feelings for themselves. This reflection is followed by dialogue with others, where the learner shares insight and findings from the personal reflection with other colleagues. Dialogue also leads to learning through the review of past and current practices. This dialogue can lead to shared understanding, the building of trust, a sense of interdependence and creative problem solving within clinical practice. Through this process, learners become more engaged in their practices and perform intentional actions.

In Active Learning, learning takes place through social and communicative processes in the workplace and in order for learning to take place that which was learnt must be practiced (Dewing, 2010). Student nurses work in the practice area for clinical experience. During their allocation to practice areas student nurses interact with patients and health care professionals. Active Learning could be used 
for the development of interpersonal skills in the very area in which the student nurses utilise these skills in order to promote a therapeutic nurse-patient relationship.

Mangold (2007) states that mentoring of learners in clinical practice offers support to student nurses in achieving the specific learning objectives and the learner receives immediate feedback on queries and performance of skills, something Generation $Y$ learners want. In Active Learning lecturers can work in collaboration with nurses in clinical practice and through professional development can facilitate the development of clinical practice and student nurses by promoting nurses in clinical practice to be mentors to student nurses. In this way the approach of Active Learning can bring about practice development.

Health care and nursing are moving towards providing evidence-based care to patients. Evidence-based nursing involves the utilisation of nursing interventions that are grounded in research evidence. One of the ways of retrieving the most recent research evidence is through electronic access. Generation $Y$ learners are at an advantage, as they have the technological understanding and skilfulness for access to research-based evidence (Lower, 2008). Through innovative teaching strategies the learner can develop skills in reading, analysing and critical thinking, which are required in the search and implementation of best practice.

\section{CONCLUSION}

Generation $Y$ learners have unique characteristics, which can either be perceived as their strengths or weaknesses. The continued enrolment of Generation $Y$ learners into higher education institutions necessitates the review of teaching strategies used by nurse educators. The development of interpersonal skills in the student nurse is integral to the fostering of a therapeutic nurse-patient relationship.

Debates, case studies, role-playing, storytelling, journaling, simulations and web page links to audio and video clips are examples of teaching strategies which belong to deconstruction pedagogies which when applied in learning can bring about critical inquiry and analytical thinking. The application of such strategies in interpersonal skill development can empower student nurses to build therapeutic nurse-patient relationships and overcome barriers to interpersonal interactions in clinical practice. 
The visual, interactive and experiential learning which can be brought about by the teaching strategies identified through the literature review complement the unique learning styles of Generation Y learners. Further, when critical inquiry is effected through a technological learning environment Generation $Y$ learners are stimulated to learn for the sake of learning and to strive to be critical, analytical professional nurses who will provide evidence based nursing.

\section{$\underline{\text { REFERENCE LIST }}$}

Aebersold, M., Tschannen, D., Stephens, M., Anderson, P., Lei, X., 2012. Second Lifeß: A new strategy in educating nursing students, Clinical simulation in nursing 8 (9), e469-e475.

Arhin, A.O., Cormier, E., 2007. Using deconstruction to educate Generation Y nursing students, Journal of nursing education 46 (12), 562-566.

Arhin, A.O., Johnson-Mallard, V., 2003. Encouraging alternative forms of self expression in the Generation $Y$ student: A strategy for effective learning in the classroom, The ABNF journal 14 (6), 121-122.

Askinazi, A., 2004. Caring for caring, Nursing forum 39 (2), 233-234.

Becker, K.L., Rose, L.E., Berg, J.B., Park, H., Shatzer, J.H., 2006. The teaching effectiveness of standardized patients, Journal of nursing education 45 (4), 103-111.

Boschma, G., Eibboden, R., Groening, M., Jackson, C., MacPhee, M., Marshall, H., Magee, K.O., Simpson, P., Tognazzini, P., Haney, C., Croxen, H., Roberts, E., 2010. Strengthening communication education in an undergraduate nursing curriculum, International journal of nursing education scholarship 7 (1), 1-14.

DeAndrea, D.C., Ellison, N.B., LaRosa, R., Steinfield C., Fiore A., 2012. Serious social media: on the use of social media for improving students' adjustment to college, Internet and higher education 15 (1), 15-23.

Department of Health, Regulations regarding the scope of practice of a registered nurse and midwife. Regulation number 786, Nursing act number 33 of 2005. 
Dewing J., 2010. Moments of movement: Active Learning and practice development, Nurse education in practice 10, 22-26.

Finfgeld-Connett, D., 2007. Meta-synthesis of caring in nursing, Journal of clinical nursing 17, 196-204.

Gibson, S., 2009. Intergenerational communication in the classroom:

recommendations for successful teacher-student relationships, Nursing education perspectives 30 (1), 37-39.

Gunderman, R.B., Brown, B.P., 2012. Teaching interpersonal and communication skills, Acad Radiol 19, 1589-1590.

Guhde, J.A., 2003. English-as-a-second language (ESL) nursing students:

Strategies for building verbal and written language skills, Journal of cultural diversity 10 (4), 113-117.

Hagerty, B.M., Patusky, K.L., 2003. Reconceptualizing the nurse-patient relationship, Journal of nursing scholarship 35 (2), 145-150.

Halldorsdottir, S., 2008. The dynamics of the nurse-patient relationship: introduction of a synthesized theory from the patient's perspective, Scandinavian journal of caring science 22, 643-652.

Johnson, D.W., 2009. Reaching out: interpersonal effectiveness and self actualisation, $10^{\text {th }}$ ed. Pearson international edition, New Jersey.

Jones, M., 2008. Developing clinically savvy nursing students: an evaluation of problem based learning in an associate degree program, Nursing education perspective 29 (5), 278-283.

Larsson, I.E., Sahlsten, M.J.M., Sjostrom, B., Lindencrona, C.S.C., Plos, K.A.E., 2007. Patient participation in nursing care from a patient perspective: a grounded theory study $21,313-320$.

Lee-Hsieh, J., Kuo, C., Turton, M.A., Hsu, C., Chu, H., 2007. Caring curriculum in Taiwan: Part II, Journal of nursing education 46 (12), 553-561. 
Legg, M.J., 2011. What is psychosocial care and how can nurses better provide it to adult oncology patients, Australian journal of advanced nursing 28 (3), 61-67.

Liu, W., Pasman, G., Stappers, P.J. Taal-Fokker, J., 2011. Supporting generation Y interaction: challenges for office work, Computer supportive cooperative work 19-23.

Lower, J., 2008. Brace yourself here comes generation Y, Critical care nurse 28 (5), 80-84.

Mangold, K., 2007. Educating a new generation teaching baby boomer faculty about millennial students, Nurse educator 32 (1), 21-23.

McKenny, K., 2011. Using an online video to teach nursing skills, Teaching and learning in nursing 6, 172-175.

Moulton, C., Tabak, D., Kneebone, R., Nestel, D., MacRae, H., LeBlanc, V.R., 2009. Teaching communication skills using the integrated procedural performance instrument (IPPI): a randomized controlled trial, The American journal of surgery 197,113-118.

O'Keeffe, G.S., Clarke-Pearson K., Council on communication and media, 2011. Clinical report - the impact of social media on children, adolescents, and family, American academy of paediatrics 127 (4), 800-804.

Oblinger, D.G., Hawkins, B.L., 2005. The myth about students, Educause Review 12-13.

Pardue, K., Morgan, P., 2008. Millennials considered: a new generation, new approaches, and implications for nursing education, Nursing education perspectives 29 (2), 74-79.

Potter, P.A., Perry, A.G., 2007. Basic nursing: Essential for practice. Mosby, St. Louis, Missouri.

Roblyer, M.D., McDaniel, M., Webb, M., Herman, J., Witty J.V., 2010. Findings on facebook in higher education: a comparison of college faculty and student uses and perceptions of social networking sites, Internet in higher education 13, 134-140. 
Searle, C., Human, S., Mogatlane, S.M., 2009. Professional practice: A South Africa perspective. Heinemann Publishers, Johannesburg.

Skiba, D.J., 2005. The millennials: have they arrived at your school of nursing?, Nursing education perspectives 25 (6), 370-371.

Stein-Parbury, J., 2000, Patient and person: developing interpersonal skills in nursing, $2^{\text {nd }}$ ed. Harcourt, Australia.

Walker, J.T., Martin, T., White, J., Elliott, R., Norwood, A., Mangum, C., Haynie, L., 2006, Generational (age) differences in nursing students' preferences for teaching methods, Journal of nursing education 45 (9), 371-374.

Ward, J., Cody, J., Schaal, M., Hojat, M., 2012. The empathy enigma: An empirical study of decline in empathy among undergraduate nursing students, Journal of professional nursing 28 (1), 34-40.

White, G., Kiegaldie, D., 2011. Generation Y learners: just how concerned should we be?, The clinical teacher 8, 263-266. 